\title{
ANALISIS FAKTOR-FAKTOR YANG MEMPENGARUHI PENDAPATAN NELAYAN KECAMATAN SEMIDANG ALAS MARAS KABUPATEN SELUMA
}

\author{
Budiman Sakti ${ }^{1}$ dan Hevi Dayanti ${ }^{2}$ \\ 1 Universitas Prof. Dr. Hazairin, SH \\ 2 Universitas Prof. Dr. Hazairin, SH \\ budimansakti63@gmail.com; 081377661222
}

\begin{abstract}
Abstrak
Tujuan penelitian ini untuk melihat pengaruh modal, tenaga kerja, pengalaman kerja dan teknologi terhadap pendapatan nelayan di Kabupaten Seluma sedangkan permasalahan yang dikaji dalam penelitian ini adalah berapa besar pengaruh modal, tenaga kerja, pengalaman kerjadan teknologi terhadap pendapatan nelayan di Kabupaten Seluma.Metode analisis yang digunakan adalah metode analisis regresi linier berganda. Hasil penelitian menunjukan bahwa modal, tenaga kerja pengalaman kerja dan teknologi secara bersama-sama mempengaruhi pendapatan nelayan di Kabupaten Seluma dengan nilai Adj-R=0,956. Koefesien regresi untuk modal adalah 0,375 berpengaruh signifisikan terhadap pendapatan, sedangkan koefisien regresi untuk tenaga kerja 3,73 adalah 0.1 juga berpengaruh signifikan terhadap pendapatan dan koefisien regresi untuk pengalaman kerja adalah 0,048 juga signifikan terhadap pendapatan. Untuk teknologi koefisien regresi adalah 0.0 yang juga berpengaruh signifikan terhadap pendapatan nelayan di Kabupaten Seluma.
\end{abstract}

Kata Kunci: Modal; tenaga kerja; pengalaman kerja; teknologi; pendapatan nelayan

\section{PENDAHULUAN}

Kabupaten Seluma sebagai bagian dari wilayah Provinsi Bengkulu memiliki potensi kelautan dan perikanan yang cukup besar. Kabupaten Seluma memiliki garis pantai yaitu kurang lebih 100 $\mathrm{Km}$ yang sangat berpotensi untuk dikembangkan sebagai sumber pendapatan daerah untuk meningkatkan pendapatan nelayan dan gizi masyarakat. Adapun potensi produksi menangkap ikan laut di Kabupaten Seluma hanya terdapat di wilayah 3 kecamatan dapat dilihat pada Tabel 1. berikut:

Tabel 1. Kecamatan Penghasil Ikan Laut di Kabupaten Seluma

\begin{tabular}{lll}
\hline Kabupaten & Produksi (Ton) & Persentasi \\
\hline Semidang Alas Maras & 90,05 & 49,54 \\
Ilir Talo & 54,98 & 30,24 \\
Seluma Selatan & 36,75 & 20,22 \\
Jumlah & 181,78 & 100 \\
\hline Sumber : BPS Kabupaten Seluma (2013)
\end{tabular}

Data Badan Pusat Stastistik di atas menerangkan bahwa jumlah produksi tangkap ikan laut di kec.Semidang Alas Maras merupakan wilayah yang paling berpotensi di Kabupaten Seluma yaitu sebanyak 49,54 persen, sedangkan kec. Ilir Talo 30,24 persen dan kec. Seluma Selatan hanya 20,22 persen. Untuk kec.Semidang Alas Maras terdapat 2 lokasi tempat pendaratan ikan (TPI) yaitu di desa Muara Maras Baru terdapat 50 nelayan dan desa Ketapang baru hanya ada 7 nelayan.

Kontribusi subsektor perikanan terhadap PDRB Kabupaten Seluma (Seluma dalam angka 2013) selama 3(tiga) tahun terakhir terus mengalami peningkatan, teknologi dibidang perikanan yang digunakan semakin berkembang dan tingkat hasil produksi juga semakin meningkat. Apabila ditinjau dari PDRB atas harga berlaku (dalam jutaan rupiah) pada tahun 2013 kontribusinya sebesar Rp. 44.109,25, tahun 2012 sebesar Rp. 36.680,52, dan tahun 2011 sebesar 36.860,63, atau masingmasing mengalami kenaikan yaitu tahun 2013 naik 11,16 persen, tahun 2012 naik 7,65 persen, dan 
tahun 2011 naik 5,99 persen. Terjadi peningkatan kontribusi perikanan dari nelayan untuk setiap tahunnya di Kabupaten Seluma, peningkatan ini tentunya tidak lepas dari kebijakan pemerintah Kabupaten Seluma dengan adanya bantuan yang diberikan oleh Dinas Kelautan dan Perikanan baik berupa bimbingan teknis maupun bantuan mesin kapal nelayan dan alat tangkap ikan yang berasal dari Dana Alokasi Khusus (DAK) Kabupaten Seluma yang merupakan program pemerintah pusat dalam rangka meningkatkan produksi-produksi perikanan laut untuk memenuhi kebutuhan permintaan laut yang setiap tahunnya terus meningkat.

\section{TINJAUAN PUSTAKA}

\subsection{Teori Usaha Nelayan}

Penangkapan ikan dan pengumpulan hasil laut lainnya merupakan mata pencarian pokok usaha nelayan. Pada dasarnya usaha penangkapan ikan yang dilakukan usaha nelayan secara teknis ekonomis merupakansuatu proses produksi yang bersifat ekstraktif, yakni mengambil hasil alam tanpa mengembalikan sebagian hasilnya untuk keperluan dikemudian hari (Mubyarto, 1985). Namun demikian tidak mesti berarti bahwa usaha perikanan rakyat merupakan usaha yang bersifat subsistem.

Nelayan adalah orang yang hidup dari mata pencarian hasil laut. Di Indonesia para nelayan biasanya bermukim di daerah pinggir pantai atau pesisir laut. Komunitas nelayan adalah kelompok yang bermata pencarian hasil laut dan tinggal di desa-desa pantai atau pesisir (Sastrawijaya,2002). Ciri komunitas nelayan dapat dilihat dari berbagai segi, yaitu:

a) Pertama, dari segi mata pencarian, nelayan adalah mereka yang aktifitasnyya berkaitan dengan lingkungan laut atau pesisir atau mereka yang menjadikan perikanan sebagai mata pencarian mereka.

b) Kedua, dari cara segi hidup, komunitas nelayan adalah komunitas gotong royong. Kebutuhan gotong royong dan tolong menolong terasa sangat penting pada saat untuk mengatasi keadaan yang menuntut pengeluaran biaya besar dan pengerahan tenaga kerja yang banyak.

c) Ketiga, meskipun pekerjaan nelayan adalah pekerjaan berat namun pada umumnya mereka dari segi keterampilan hanya memiliki keterampilan sederhana. Kebanyakan dari mereka bekerja sebagai nelayan adalah profesi yang diturunkan oleh orang tua, bukan dipelajari dengan profesional.

\subsection{Teori Produksi}

Teori produksi yang sederhana menggambarkan tentang hubungan di antara tingkat produksi suatu barang dengan jumlah tenaga kerja yang digunakan untuk menghasilkan berbagai tingkat produksi barang tersebut. Dalam analisis tersebut dimisalkan bahwa faktorfaktor produksi lainnya adalah tetap jumlahnya, yaitu modal dan tanah jumlah dianggap tidak mengalami perubahan. Satu-satunya faktor produksi yang dapat diubah jumlahnya adalah tenaga kerja (Sukirno,2004).

\section{METODE}

Sifat penelitian ini adalah penelitian (explanatory research), yaitu penelitian yang menjelaskan pengaruh antara variabel bebas yaitu: Modal kerja, tenaga kerja, pengalaman kerja, dan teknologi terhadap variabel terikat yaitu pendapatan nelayan di Kecamatan Semidang Alas Maras Kabupaten Seluma secara kuantiatif. Sampel penelitian diambil dari usaha nelayan yang ada di Kecamatan Semidang Alas Malas sebanyak 57 responden usaha nelayan.

\section{HASIL DAN PEMBAHASAN}

\subsection{Modal Kerja Terhadap Pendapatan}


Berdasarkan responden usaha nelayan di Kabupaten Seluma, responden memiliki modal terbanyak yaitu 34 responden dengan modal Rp.11.000.000 s.d Rp.15.000.000 dengan memiliki pendapatan sebesar Rp.11.000.000 s.d Rp.20.000.000 Responden terendah berada pada klasifikasi modal Rp.11.000.000 s.d Rp.15.000.000 dengan pendapatan sebesar Rp.5.000.000 s.d Rp.10.000.000 yaitu sebanyak 2 responden dan klasifikasi modal Rp.16.000.000 s.d Rp.20.000.000 dengan pendapatan yang diperoleh sebesar lebih dari Rp.30.000.000 hanya 1 responden.

Tabel 4.1. Modal Kerja Terhadap Pendapatan

\begin{tabular}{lllll}
\hline Modal Kerja (Juta) & \multicolumn{4}{c}{ Pendapatan (juta) } \\
\cline { 2 - 5 } & $5-10$ & $11-20$ & $21-30$ & $>30$ \\
\hline $5-10$ & 8 & 4 & - & - \\
$11-15$ & 2 & 34 & & - \\
$16-20$ & - & 3 & 5 & 1 \\
Total & $\mathbf{1 0}$ & $\mathbf{4 1}$ & $\mathbf{5}$ & $\mathbf{1}$ \\
\hline
\end{tabular}

Sumber : Data Primer Responden Usaha Nelayan Kabupaten Seluma (2015)

Pada klasifikasi modal Rp.5.000.000 s.d Rp.10.000.000 terdapat 8 responden yang berpendapatan Rp.5.000.000 s.d Rp.10.000.000, disusul 4 responden yang berpendapatan Rp.11.000.000-Rp.20.000.000 Untuk klasifikasi modal Rp.16.000.000 s.d Rp.20.000.000 terdapat 3 responden yang memperoleh pendapatan kisaran Rp. 11.000 .000 s.d Rp.20.000.000 per bulan dan 5 responden memperoleh kisaran Rp.21.000.000 s.d Rp.30.000.000 perbulan.

\subsection{Tenaga Kerja Terhadap Pendapatan}

Terdapat 7 responden yang berpenghasilan Rp.5.000.000s.d Rp.10.000.000,yang menggunakan tenaga kerja antara 1 s.d 3 orang, sedangkan pada pendapatan Rp.11.000.000 s.d Rp.20.000.000, dengan tenaga kerja 1 s.d 3 orang terdapat 5 jumlah responden, dan tidak terdapat responden yang berpendapatan Rp.21.000.000 s.d Rp.30.000.000 dan >Rp.30.000.000 dengan tenaga kerja yang berjumlah 1 s.d 3 orang.

Tabel 4.2. Tenaga Kerja Terhadap Pendapatan

\begin{tabular}{lllll}
\hline Tenaga Kerja (orang) & \multicolumn{4}{c}{ Pendapatan (juta) } \\
\cline { 2 - 5 } & $5-10$ & $11-20$ & $21-30$ & $>30$ \\
\hline $1-3$ & 7 & 5 & - & - \\
$4-6$ & 3 & 33 & 1 & - \\
$>6$ & - & 4 & 3 & 1 \\
Total & $\mathbf{1 0}$ & $\mathbf{4 2}$ & $\mathbf{4}$ & $\mathbf{1}$
\end{tabular}

Sumber : Data Primer Responden Usaha Nelayan Kabupaten Seluma (2015)

Dapat dilihat pada tabel 4.2. diatas bahwa usaha nelayan yang mempunyai tenaga kerja kisaran 4 s.d 6 orang terdapat 3 responden yang berpenghasilan Rp.5.000.000 s.d Rp.10.000.000, dan pada pendapatan Rp.11.000.000 s.d Rp.20.000.000, dengan tenaga kerja 4 s.d 6 orang terdapat 33 responden dan merupakan pendapatan yang paling banyak respondennya. Pada pendapatan Rp.21.000.000 s.d Rp.30.000.000,yang mempunyai tenaga kerja dengan jumlah 4 s.d 6 orang hanya terdapat 1 responden, dan untuk angka pendapatan di atas Rp.30.000.000 yakni tidak ada satu jawaban responden.Dengan demikian usaha nelayan yang jumlah tenaga kerja yang berkisar 1 s.d 3orang dan 4 s.d 6 orang serta $>6$ orang rata- rata berpenghasilan dikisaran angka Rp.11.000.000, sampai Rp.20.000.000 dilihat dari jumlah responden sebesar 42 orang dari 57 sampel. 
4.3 Pengalaman Kerja Terhadap Pendapatan

Responden yang telah berpengalaman antara 5-9 tahun yang berpenghasilan kisaran Rp.5.000.000-Rp.10.000.000,terdapat 3 jumlah responden, sedangkan pada penghasilan Rp.11.000.000-Rp.20.000.000, dengan pengalaman kerja 5-9 tahunmemiliki responden lebih banyak yaitu 13 responden.

Tabel 4.3. Pengalaman Kerja Terhadap Pendapatan

\begin{tabular}{lllll}
\hline $\begin{array}{l}\text { Pengalaman Kerja } \\
\text { (Tahun) }\end{array}$ & \multicolumn{4}{c}{ Pendapatan (juta) } \\
\cline { 2 - 5 } & $5-10$ & $11-20$ & $21-30$ & $>30$ \\
\hline $5-9$ & 3 & 13 & - & - \\
$10-14$ & 6 & 19 & 1 & 1 \\
$>15$ & 1 & 10 & 3 & - \\
Total & $\mathbf{1 0}$ & $\mathbf{4 2}$ & $\mathbf{4}$ & $\mathbf{1}$ \\
\hline
\end{tabular}

Sumber : Data Primer Responden Usaha Nelayan Kabupaten Seluma (2015)

Namun pada pengalaman kerja antara 10 s.d 14 tahun dengan pendapatan Rp.5.000.000Rp.10.000.000terdapat 6 responden. Untuk pendapatan berkisar antara Rp.11.000.000 s.d Rp.20.000.000 dengan pengalaman kerja 10 s.d 14 tahun terdapat 19 responden, dan masingmasing 1 responden pada pendapatan yang berkisar Rp.21.000.000 s.d Rp.30.000.000 dan lebih dari Rp.30.000.000, dengan pengalaman kerja 10-14 tahun.

Sedangkan responden yang berpengalaman lebih dari 15 tahun ada satu responden dengan penghasilan Rp.5.000.000 s.d Rp.10.000.000, pendapatan lebih dari Rp.30.000.000, tidak ada satu pun jawaban responden tetapi pada pendapatan yang berkisar Rp.11.000.000 s.d Rp.20.000.000 denganjumlah responden sebesar 10, dan 3 responden yang berpendapatan Rp.21.000.000-Rp.30.000.000,dengan pengalaman kerja lebih dari 15 tahun.

\subsection{Teknologi Terhadap Pendapatan}

Jumlah teknologi digunakan usaha nelayan yang terdapat pada tabel 4.4 yang berkisar antara 1-5 unit dengan pendapatan antara Rp.5.000.000-Rp.10.000.000terdapat 4 responden, sedangkan terdapat 11 jumlah responden yang berpenghasilan antara Rp.11.000.000Rp.20.000.000 per bulan dengan teknologi 1-5 unit.

Tabel 4.4. Teknologi Terhadap Pendapatan

\begin{tabular}{lllll}
\hline Teknologi (Unit) & \multicolumn{4}{c}{ Pendapatan (juta) } \\
\cline { 2 - 5 } & $5-10$ & $11-20$ & $21-30$ & $>30$ \\
\hline $1-5$ & 4 & 11 & - & - \\
$6-10$ & 5 & 30 & 2 & 1 \\
11 & - & 2 & 2 & - \\
Total & $\mathbf{9}$ & $\mathbf{4 3}$ & $\mathbf{4}$ & $\mathbf{1}$ \\
\hline
\end{tabular}

Sumber : Data Primer Responden Usaha Nelayan Kabupaten Seluma (2015)

Terdapat 30 responden yang berpenghasilan Rp.11.000.000-Rp.20.000.000,yang menggunakan jumlah teknologi sebesar 6-10 unit, tetapi pada pendapatan Rp.5.000.000Rp.10.000.000sebanyak 5 responden dan untuk pendapatan Rp.21.000.000-Rp.30.000.000, masing-masing mempunyai 2 responden, dan 1 responden dengan pendapatan diatas Rp.30.000.000perbulan.

Jumlah teknologi pada usaha nelayan yang berjumlah diatas 11 unit hanya ada pada usaha nelayan yang berpendapatan Rp.11.000.000-Rp.20.000.000 yakni berjumlah 2 responden dan 2 responden pada tingkat pendapatan yang berkisar pada angka Rp.21.000.000Rp.30.000.000, untuk pendapatan selebihnya tidak ada satupun responden 


\section{KESIMPULAN}

Berdasarkan hasil penelitian yang telah dilakukan pada variabel modal kerja,tenaga kerja, pengalaman kerja, dan teknologi terhadap pendapatan usaha nelayan di Kecamatan Semidang Alas Maras Kabupaten Seluma, maka dapat disimpulkan bahwa:

1. Variabel modal kerja berpengaruh signifikan terhadap pendapatan usaha nelayan di Kecamatan Semidang Alas Maras Kabupaten Seluma. Semakin tinggi modal usaha, semakin besar peluang mendapatkan hasil tangkapan yang lebih banyak.

2. Variabel tenaga kerja signifikan mempengaruhi pendapatan usaha nelayan di Kecamatan Semidang Alas Maras Kabupaten Seluma,hal ini dikarenakan tenaga kerja sangat dibutuhkan dalam menangkap ikan dan untuk pengangkatan jaring dibutuhkan tenaga manual yang langsung dari tenaga kerja sendiri, sehingga dapat memaksimalkan hasil tangkapan dari usaha nelayan.

3. Variabel pengalaman kerja secara positif dan signifikan berpengaruh terhadap pendapatan usaha nelayan di Kecamatan Semidang Alas Maras Kabupaten Seluma, semakin lama pengalaman usaha nelayan semakin besar pula pendapatan dari hasil tangkapan ikan yang lebih banyak.

4. Variabel teknologi secara positif dan signifikan berpengaruh terhadap pendapatan usaha nelayan di Kecamatan Semidang Alas Maras Kabupaten Seluma karena semakin banyak teknologi yang digunakan terutama pada teknologi penerangan (lampu) maka akan semakin besar pula peluang mendapatkan hasil tangkapan yang lebih banyak sehingga meningkatkan pendapatan nelayan.

\section{REFERENSI}

\section{Artikel :}

Imron, M, (2003).Kemiskinan dalam Masyarakat Nelayan. Jurnal Masyarakat dan Budaya.PMB-LIPI.

\section{Buku :}

Algifari. (2000). Analisis Regresi: Teori, Kasus, dan Solusi. Edisi 2. Yogyakarta: BPFE.

Indriantoro., \& Supomo. (1999). Metodologi Untuk Aplikasi dan Bisnis. Yogyakarta: BPFE.

Joesran,F. (2003). Teori Ekonomi Mikro. Jakarta: Selemba Empat.

Kusnadi. (2003). Akar Kemiskinan Nelayan.Yogyakarta: LKIS.

Miller,R.L.,\&Meiners, R.E. (1999).Teori Ekonomi Mikro. Edisi Ketiga. Jakarta: LP Fakultas Ekonomi Universitas Indonesia.

Raharjha. M.(2006).Teori Ekonomi Mikro,Edisi ketiga, Jakarta: LP Fakultas Ekonomi UI. Jakarta.

Said, A.H.(2003).Analisis Masalah Kemiskinan dan Ketimpangan Pendapatan Nelayan di Medan Belawan, Sumut. Tesis S2. Medan: PPS USU.

Sasmita.(2006). Analisis Faktor-faktor Yang Memengaruhi Usaha Nelayan di Kabupaten Asahan. Tesis S2. Medan: PPS USU. 
EQUITY, Vol.06 no (02): page 25-30, Des 2018

For an organizational or government report or document with no author :

Badan Pusat Satistik. (2013). Seluma Dalam Angka. Kabupaten Seluma: Badan Pusat Statistik. 